\title{
NOTAS
}

\section{Tendencias de la crítica borgiana}

Ya no hay lectores sino críticos. Toda obra suscita hoy tal furor de análisis y de interfretación que pasa a ser objeto de interminables disecciones. Pero se ha perdido quizá el verdadero goce estético que ella comunica. No sin cierta melancólica ironía el propio Borges ha escrito que "los buenos lectores son cisnes aún más tenebrosos y singulares que los buenos autores". Habría que añadir también: que los buenos críticos. Y es justamente la obra misma de Borges una de las que ha padecido más esta ausencia. No nos asombra, por ello, ver a través del espejo crítico a un Borges incesantemente refractado. Hay críticos que ya resultan más borgianos que Borges, por el exagerado gusto de los "laberintos del espíritu"; han extremado tanto las sutilezas y las exégesis que no es aventurado pensar en el malentendido. El mito de un Borges esotérico, extraño alquimista del lenguaje, inteligencia suprema y calculadora de los más mínimos detalles de su obra, no pasa de ser elaboración intelectualizante. Borges mismo no ha ocultado su perplejidad ante este tipo de crítica, y ha dicho en una ocasión: "Hay que ser algo inocente. La creación tiene que realizarse como soñando". La obra, para él, no nace de una delibetación; es el resultado de un proceso más enigmático. También ha afirmado: "En el decurso de una vida consagrada menos a vivir cue a leer, he verificado muchas veces que los propósitos y teorías literarias ne son otra cosa que estímulos y que la obra final suele ignorarlos y hasta contradecirlos." Esa inocencia tiene, además, especial sentido dentro de su concepción del creador que a su vez es criatura de otro creador: la intuición de que el escritor, como el hombre mismo, ignora su destino. En una de sus parábolas de El Hacedor, Borges figura a un Shakespeare que a la hora de morir pide a Dios que lo deje ser "uno y yo"; Dios le responde: "Yo tampoco soy yo; yo soñé el mundo como tú 
soñaste tu obra, mi Shakespeare, y entre las formas de mi sueño estás tú, que como yo eres muchos y nadie."

Otro de los mitos creados en torno a la obra de Borges es el de la erudición. Si bien nadie niega esa erudición y siempre habría que ver en Borges al creador-lector, parece imposible pasar inadvertido el hecho de que Borges maneja esa erudición con sus propios fines estéticos: la convierte en un material íntimo y vivido, la recrea dentro de un sentido ficticio. Y por ello no sólo la maneja creadotamente, sino que con frecuencia la inventa. "Poco interesa a Borges la insípida tarea de fabricar supercherías", afirma de manera concluyente un crítico. ${ }^{1}$ Esa "insípida tarea". es, siń embargo, una de las inclinaciones más constantes de Borges y constituye justamente una de las claves de su espíritu lúdico. Es, sobre todo, uno de los recursos de que se vale Borges para crear una tensión en su obra entre lo real y lo irreal, entre lo positivo y lo inventado. En "Tres versiones de Judas", por ejemplo, se suscita el tema de la identidad: ¿fue Judas realmente un simple traidor o encarnó, por el contrario, al verdadero Cristo? El relato es típico de Borges porque se basa precisamente en un juego de erudición constante: citas y conceptos que continuamente se enfrentan entre sí. Pero el lector tiene la clave de todo este juego intelectual cuando se da cuenta de que una de las obras que entran en este proceso teológico a lo Borges es nada menos que la "Vindicación de la eternidad", de Jaromir Hladík, que no es más que una de las ficciones de Borges y personaje central de otro cuento suyo: "El milagro secreto". Es decir, que Borges con la erudición no hace sino internarnos en un laberinto dialéctico donde el lector comienza por sentirse perdido y, por ello mismo, comienza a encontrarse. Pero, claro, Borges no lo hace por simple superchería. Hay en él una actitud más profunda. Como lo ha expresado admirablemente Jean Wahl: "Plus qu'une science, ce que Borges nous propose, c'est un profond questionnement, une profonde ignorance". ${ }^{3}$ De manera que la llamada "crítica de fuentes" tendría muy poca eficacia frente a la obra de Borges. En todo caso, no sería tan iluminadora. ¿Y es que lo ha sido alguna vez este tipo de crítica? Ya Eliot manifestaba su reticencia respecto a ella cuando decía que toda obra auténtica es un hecho nuevo y nada de lo que la antecede - biografía del autor, lecturas, etc.- puede explicarla.

La crítica borgiana verdadera es aquella que se funda en los textos de Borges y lo que ellos proponen. Se ha hecho ya, por supuesto, y de manera admirable, por parte de algunos críticos. No importa que esa

1 Marcial Tamayo y Adolfo Ruiz-Díaz: Borges, enigma $y$ clave (Buenos Aires, Nuestro Tiempo, 1955), p.

2 Cf. Cabiers l'Herne: Jorge Luis Borges, París, 1964. 
crítica no llegue a apreciaciones parecidas entre sí. Ello está quizá en la naturaleza misma de la obra borgiana: una obra dialéctica y contradictoria. En general, esta crítica parece bifurcarse en dos tendencias. Los que creen que la obta de Borges es la continua expresión de un caos y de una visión laberíntica del mundo. Ana María Barrenechea asume, principalmente, esta perspectiva. ${ }^{3}$ Quizás Octavio Paz se aproxime también a este punto de vista, pero con un sentido más signifícativo y revelador. Para Paz, la modernidad no es la aceptación de un sistema sino la confrontación y la crítica de todos los sistemas; por ello, dice, la obra del escritor moderno se resuelve en una negación. Así, Borges es el "autor de una obra única, edificada sobre el tema vertiginoso de la ausencia de obra"." (Si pensamos en la poesía de Borges, nos damos cuenta de la veracidad de esta idea de Paz. La poesía de Borges es justamente la poesía sobre la ausencia del poema y sobre ello poetiza: "Has gastado los años y te han gastado, / Y todavía no has escrito el poema"). Peto existe también la perspectiva de los que, sin negar esta visión laberíntica o este radicalismo de la obra como ausencia de obra, conciben una dialéctica en Borges que va continuamente del caos al orden y que quizá, finalmente, propone una coherencia superior: una cosmovisión en la que todos los contratios se anulan, se neutralizan o se convierten en el otro. Uno de los primeros, Emir Rodríguez Monegal ha expuesto esta idea - a la que sólo le faltaría un desarrollo más exhaustivo- en su ensayo "Borges y la literatura fantástica". ${ }^{5}$

Pero también Jaime Alazraki, en su reciente libro La prosa narraíva de Jorge Luis Borges, ${ }^{6}$ adhiere a esta perspectiva. $\mathrm{Y}$ en las conclusiones de la primera parte de su estudio, la expone de manera muy precisa: "Borges, al mostranos que la ordenación del mundo es un prurito de la inteligencia humana y que el universo es un caos impenetrable; al insinuar que nuestra realidad bien puede ser el sueño de Alguien; al reducir nuestro destino a palabras ya escritas en el libro de una voluntad suprema; al absorber nuestra identidad en una identidad única que las contiene a todas y al presentar la posibilidad de que todo es todo y una moneda el universo; al negar el tiempo; al ver en todas las cosas un resumen del universo; al definir los capítulos de la historia como concéntricas repeticiones de un círculo que retorna infinitamente, crea un sistema de opo. siciones cuyo objeto sería demostrar el absoluto relativismo de las cosas".

3 La expresión de la iryealidad en la obra de J. L. Borges (México, El Colegio de México, 1967.

4 Corriente alterna (México, Ed. Siglo XXI, 1967), p. 40.

5 Narradores de esta Américut (Montevideo, Alfa, 1962).

- Madrid, Editorial Gredos, 1968. 
Y luego añade: "Este relativismo arranca de un escepticismo esencial pero, como lo hemos visto, sus consecuencias son fecundantes. Borges ha enseñado que los axiomas de la metafísica y las revelaciones de la teología valen como creaciones de la imaginación humana pero que distan mucho de ser verdades eternas. Ha enseñado a descreer de los absolutos ( $\tan$ cerca de los absolutismos). Sus "ficciones", que a muchos les parecen tan ajenas a la realidad y a la vida, nos acercan más estrechamente a la realidad." 7

Ahora bien, esta idea esencial a que llega Alazraki es el resultado de una paciente penetración en los textos narrativos de Borges, así como en algunos de sus ensayos. Su libro parece mantener una estructura tradicional: análisis de los temas y, luego, del estilo narrativo borgiano. Esta división podría parecer un tanto simple: recuerda la división de la obra entre fondo y forma. Pero Alazraki muy pocas veces cae en este simplismo. Su análisis de la temática borgiana, es cierto, se mantiene al nivel de lo obvio y evidente, sin dejar de recurrir a las consabidas fuentes, pero también, $y$ esto es lo valioso, va extrayendo de ella la concepción del mundo que nutre toda la obra de Borges. Luego su estudio se interna en los aspectos estilísticos, campo sin duda difícil de la crítica por los falsos presupuestos en que puede fundarse: reducir el etilo de un autor a sus simples hábitos verbales o esa supersticiosa ética del lector, de que hablaba el propio Borges, de que el estilo es sólo lenguaje bello y decoración metafórica. Pero Alazraki se cuida bien de someterse a estas aberraciones. Por el contrario, logra precisar con toda claridad lo que es el estilo para Borges: eficacia y economía expresivas, estilo neutro, dominado por las imposiciones del tema. Es decir, el estilo sin estilo en el sentido convencional. Pero luego no deja de sorprender que crea encontrar en las figuras retóricas de Borges - la metonimia, la sinécdoque, etc.- los fundamentos de su estilo. Justamente, creemos que para Borges si el estilo es siempre lenguaje, también lo trasciende. $Y$ con ello Borges se adelantaba a muchos de los estructuralistas contemporáneos. Su concepción es igual a la de Roland Barthes en su libro "Le degré zéro de l'écriture. "Sous le nom de style - dice Barthes-, se forme un lanage autarcique qui ne plonge que dans $\mathrm{l}$ mythologie personelle, et secréte de l'auteur, dans cette hypophysique de la parole, oú se forme le premier couple des mots et des choses, oú s'installent une fois pour toutes les grands thémes verbaux de son existence". (Marginalmente, hay que decir que Alazaraki hace uso del concepto de "degré zéto de l'écriture", p" ro lo pone en boca de un autor inglés sobre la novela francesa;

${ }_{7}$ lbid, pp. 116-117. 
lo cual explica quizá que no haya tomado en cuenta todas las implicaciones de este concepto, hoy $\tan$ fundamental en la crítica literaria.)

Finalmente, hay que decir que en el libro de Alazraki no penetra en la relación de Borges con su obra. No es un reproche que le hacemos, sino una simple constatación. Y una manera de llamar la atención sobre este tema que podría ser clave para iluminar todo el mundo borgiano. No pretendemos, por supuesto, que se haga una crítica biográfica a lo Sainte-Beuve. Eso ya no tiene sentido. Además no se trata de ver a Borges dentro de su vida cotidiana y parcial, sino dentro del universo de sus propias ficciones. Son esas ficciones las que nos dan el verdadero rostro de Borges: su yo simbólico y profundo. Es un yo creado por su obra y que vive a expensas del otro Borges de carne $y$ hueso que pasea por Buenos Aires, según el mismo lo ha explicado en el texto "Borges y yo". Queremos decir también que Borges no es ese diletante, inquisidor de bizantinismo, que muchos creen ver en él. Su espíritu lúdico no debe ocultarnos. el fondo dramático de donde nacen todas sus creaciones. El insomnio, las pesadillas, los delirios y los laberintos que pueblan su obra parecen surgir de su propio mundo interior: son los laberintos y las pesadillas de Borges (del otro, del que escribe). Y por ello quizá, para él, el arte es una compensación. Así lo expresa o (insinúa) en el primer texto de "El Hacedor", en torno a Homero. $Y$ también en esta frase - una de las más memorables, según él mismo, que le ha tocado conocer- - y que él adjudicaba a Hudson: muchas veces en la vida emprendió el estudio de la metafísica, pero siempre lo interrumpió la felicidad. Señalo este tema de un posible psicoanálisis (¿existencial?) de la obra de Borges, porque realmente parece fecundo en implicaciones. Por lo demás, ya el propio Emir Rodríguez Monegal lo ha esbozado en el ensayo que hemos citado. Sin duda, es uno de los temas que cambiaría muchas de las actuales perspectivas críticas frente a la obra y el mundo borgianos.

University of Pittsburgh

Guillermo SuCRE 
